D:\Nsurg \Vol. 24, No. 1, Jan. - Mar., 2020\Nsurg-13.Doc $\quad$ (A) $\quad$ P. $82-86 \quad$ III

ORIGINAL ARTICLE

\title{
Positive Predictive Value of Magnetic Resonance Imaging in Intradural Spinal Tumors Taking Histopathology as Gold Standard
}

\author{
HAFEEZ-UR-REHMAN', ADNAN YOUSAF ${ }^{2}$, MUHAMMAD USMAN ${ }^{3}$, \\ MUHAMMAD NOUMAN AKRAM ${ }^{4}$, IRUM HABIB ${ }^{5}$, SARFARAZ AHMAD ${ }^{6}$ \\ ${ }^{1}$ Gajju Khan Medical College, Swabi. Pakistan. \\ ${ }^{2}$ Burns Trauma Center, Hayatabad Medical Complex, Pakistan. \\ ${ }^{3}$ Department of Neurosurgery, Lady Reading Hospital, Peshawar, Pakistan. \\ ${ }^{4}$ Sahara Medical College, Narowal, Pakistan. \\ ${ }^{5}$ Nowshera Medical College, Nowshera. \\ ${ }^{6}$ Khawaja Safdar Medical College, Sialkot, Pakistan
}

DOI: $10.36552 /$ pjns.v24i1.418

\section{ABSTRACT}

Objective: To observe the positive predictive value of MRI, taking histopathology as gold standard in detecting spinal intradural tumors.

Materials and Methods: Total 180 cases were included through non-probability purposive sampling, at Ganga Ram Hospital, Radiology department, Lahore. The radiological diagnosis obtained through MRI, was observed. The cases fit in inclusion criteria were underwent surgery and their histopathological findings were observed. Comparison between the outcomes of MRI and histopathology were undertaken, keeping histopathology as gold standard. Positive predictive value of MRI in the diagnosis of intradural spinal tumor was calculated and presented in the form of percentages and frequency.

Results: There were total 180 patients presenting in OPD with the mean age of $45.71 \pm 13.57$ years. There were $112(62 \%)$ male. Male to female ratio was 1.6:1. There were 134 (74.4\%) cases who were positive for malignant spinal intradural tumor on histopathology showing the PPV of MRI as $74.4 \%$.

Conclusion: Magnetic Resonance Imaging is very beneficial imaging tool for early diagnosis of spinal cord tumors.

Keywords: Spinal Tumors, Magnetic Resonance Imaging, Histopathology, Malignant Tumors.

\section{INTRODUCTION}

Spinal tumor can be described as cells (mass) of abnormal growth, in the cord or its surroundings. Surgical intervention is required to relieve the compression in patients where the spinal cord compression results in neurological compromise in the form of radiculopathy, myelopathy or radiculomyelopathy. ${ }^{1}$
The classification of spinal tumors is in two main groups: intradural and extradural. ${ }^{2}$ With respect to anatomical co relation to the parenchyma, intradural spinal tumors are further classified into intramedullary (within the cord) and extramedullary (outside the cord) tumors. The diverse histology of the spinal intradural compartment, permits the development of tumors, Date of Submission: 2-2-2020 cells of spinal vasculature and Date of Printing: 31-3-2020 
The spinal intradural tumors especially in pediatric population has predilection to be associated with osseous abnormalities such as scalloping and other disorders of the vertebral body and kyphoscoliosis. ${ }^{4} \mathrm{Of}$ all the spinal tumors, extramedullary tumors are found be more common (50-60\%) than intramedullary tumors (7-22\%). Meningioma and neurofibroma are the most common, making 80-90\% of intradural extramedulary tumors. Others are lipoma, dermoid and epidermoid. Of the intramedullary tumors astrocytoma are $30 \%$ and ependymoma are $29 \%$. $^{5}$

The prevalence of intramedullary tumors is $4-$ $10 \%$ of all the tumors of CNS. In adults their frequency is $25 \%$, while in pediatrics it is as high as about $50 \%$ of the intradural spinal tumors. ${ }^{6}$

Untreated spinal tumors can result in compromised neurological outcome in the form of morbidity and mortality. Consequently, the role of precise diagnosis in defining prognosis as well as management is very pivotal. In last two decades' substantial developments has happened in different modalities of radiology for diagnosing spinal tumors. Radiological imaging is now an important armamentarium for correct diagnosis and management. Wide range of different imaging tools are in practice and of those CT and MR scan are the efficient tools for early diagnosis of spinal cord tumors. $^{7}$

MRI provides crucial information regarding the exact location, extent and internal composition of lesion, thus smartly narrowing the differential diagnosis and guiding surgery. ${ }^{8}$

The demand of biopsy pre-operatively, could be easily avoided because of the fact that the accurate radiological diagnosis can be obtained with the help of MRI. ${ }^{7}$ The preoperative MRI evaluation of spinal lesions has become the standard of care now days in spinal cord surgical centers. ${ }^{8}$

In a study by De-Verdelhan O et al, MRI shows diagnosis of schwanomma with a specificity of $83.3 \%$, sensitivity of $96.4 \%$, and a negative predictive value of $95.7 \%$, while a positive predictive value of $87.1 \% .^{9,10}$

A study conducted in Peshawar ${ }^{6}$ only documented MRI findings of intradural spinal tumors. As the positive predictive value depends on the disease prevalence so the rationale of my study is to study this magnitude in our set of population as no local statistics is available. Also this study was conducted with the objective to determine the positive predictive value of MRI in detection of intradural spinal tumors, while considering histopathology as gold standard.

\section{MATERIAL \& METHODS}

\section{Study Design \& Sample Size}

In this cross sectional descriptive study, a total of 180 cases were studied at the Radiology Department of Sir Ganga Ram Hospital, Lahore. Sample size was calculated with an expected positive predictive value of MRI i.e. $87 \%$ for diagnosis of intradural spinal tumors, using 95\% confidence interval and 5\% margin of error. ${ }^{9}$ Ethical approval was taken and the duration of the study was 6 months (January 2018 - June 2018). Patients were recruited by non-probability consecutive sampling technique.

\section{Inclusion Criteria}

Patients having age range 10 to 70 years, of either gender and with clinical suspicion of intradural spinal tumor such as neck pain, backache, quadriplegia or paraplegia referred by neurosurgeon and found positive on MRI for intradural spinal tumor, were included.

\section{Exclusion Criteria}

Those patients, having contraindication to MRI, like brain aneurysm coils and clips, cardiac prosthetics, patients with suspicion of metastatic tumor, having primary tumor elsewhere in the body, patients previously operated and post traumatic patients were excluded from the study.

\section{Methods}

Any intradural intra or extra medullary tumor will be labeled positive case. A normal MRI or non-tumorous lesions (hemorrhage, infections) will be labeled as negative.

$$
\text { PPV }=\frac{\text { True }+ \text { ve }}{(\text { True }+ \text { ve })(\text { False }+ \text { ve })}
$$

True positive is a presence of intradural spinal tumor characterized on MRI and confirmed on histopathology.False positive is apresence of intradural spinal tumor on MRI however negative on histopathology.

The Meningioma MRI features are: iso on T1, while iso to slightly hyperintense on $\mathrm{T} 2$ Weighted Images to spinal cordand shows uniform homogeneous enhancement after I/V contrast.On Histopathology, meningioma shows small foci of neoplastic cells, having high nuclear cytoplasmic ratio and also demonstrates increased cellularity. 
The Neurofibroma MRI features are: hypo on T1, while hyperintense to spinal cord on T2WI with central area of low signal and hyperintense rim ("target sign") and having heterogenous contrast enhancement. Neurofibromas on histopathology shows spindle-shaped cells and fusiform comma-shaped nuclei, which are distributed on connective tissue matrix background.

On MRI lipomas are hyperintense on T1WI, High on T2WI, hypointense on fat saturated sequences with no or minimal enhancement. On Histopathology Lipomas show bland a cellular stroma with neoplastic cells that lack cellular atypia. Dermoid Cysts on MRI: hypo or hyperintense on T1WI, hyperintense on T2WI, hyper-intense on FLAIR and show no or mild rim enhancement.On Histopathology, the hallmark of these cysts is the presence of pilosebaceous structures in the cyst wall. Hair shafts are often found within the cyst.

Ependymoma are iso to hypo on $\mathrm{T} 1$, while hyperintense to the spinal cord on T2WI on MRI and after I/V contrast shows homogenous enhancement. While histologic examination shows uniform hyperchromatic nuceli along with perivascular pseudorosettes.

Astrocytoma is iso to hypo on T1, while hyperintense on $\mathrm{T} 2$ and shows patchy enhancement after I/V contrast on MRI. On histopathology astrocytomas are depicted by hyper cellularity and absence of surrounding capsule.

\section{Data Collection}

Patients referred by Neurosurgeons from the OPD of Ganga Ram Hospital, Lahore, having clinical suspicion of spinal tumors and also meeting the parameters of inclusion were included. Informed consent was taken from all the patients were taken for inclusion in the study. The demographics like, gender age and address were taken from the patients.

MRI was carried out on 1.5-T machine, with T1, $\mathrm{T} 2$ and T1 with contrast sequences both sagittal and axial cuts. MRI diagnosis like absence or presence of intradural spinal tumor and other MRI findings i.e. compartment and location was recorded.

Only the positive case underwent surgery and histopathology reports were documented. The results of histopathological diagnosis and MRI findings were matched, while keeping the fact in view that histopathology is gold standard.

\section{Data Analysis}

The quantitative variables like age, mean \pm standard deviation was calculated, while qualitative variables like gender, MRI diagnosis i.e. absence or presence of intradural spinal tumor and histopathology results i.e. absence or presence of intradural spinal tumor, frequencies and percentages was calculated. Positive predictive value of MRI for diagnosing intradural spinal tumor was calculated and documented as frequencies.

\section{RESULTS}

Total 180 patients presenting in OPD with the mean age of $45.71 \pm 13.57$ years. Minimum age of patients was noted as 19 years while maximum age was noted as 70 years.

There were $112(62 \%)$ male and 68 (38\%) females with male-to-female ratio of 1.6:1.

Mean age and standard deviation of male and female patients was $46.47 \pm 12.84$ years and $44.44 \pm$ 14.69 years respectively.

There were 134 (74.4\%) cases who were positive for malignant brain tumor on histopathology while 46 (25.6\%) cases had benign condition (Table 1).

Table 1: Distribution of findings on histopathology.

\begin{tabular}{|l|l|c|c|}
\hline \multicolumn{2}{|c|}{} & Frequency & Percentage \\
\hline \multirow{3}{*}{ Histopathology } & Present & 134 & $74.4 \%$ \\
\cline { 2 - 4 } & Absent & 46 & $25.6 \%$ \\
\cline { 2 - 4 } & Total & 180 & $100.0 \%$ \\
\hline
\end{tabular}

\section{DISCUSSION}

Spinal tumors comprise of $10-20 \%$ of all primary central nervous system tumors and of all these only $20 \%$ are intramedullary tumors. ${ }^{11-13}$

Spinal tumors result in compression of spinal cord when they grow to certain size and causes sensory and motor loss. There are large number of studies and literature about intramedullary spinal cord tumors but few studies are also present about tumor mimicking nonneoplastic intramedullary spinal cord lesions. These lesions include sarcoidosis, vascular malformations, amyloid angiopathy, tuberculoma, abscess, cord ischemia and demyelinated lesionsas well. Among this literature very rare are 
intramedullary non-neoplastic inflammatory spinal cord lesions. ${ }^{14,15}$

MRI is extremely subtle radiological modality of choice for detecting spinal cord tumors. MRI suggests diagnosis on background of imaging features alone or in combination with demographic data. Post operative histopathology is still necessary in every case to get definite diagnosis. ${ }^{16}$

Thus we aimed to conduct this study in patients presented with positive on MRI. In the current study, out of 180 total patients, $62 \%$ were male while $38 \%$ females, with male to female ratio of 1.6:1. This showed that there were more males who are more prone to spinal tumors as compared to females. Studies suggest that there is slight male preponderance for primary spinal tumors. Similarly, infections of the spinal cord were also 2.5 times more in males than in females, reported in a study. ${ }^{11}$

The diagnosis of spinal cord tumors has been significantly improved after advent of MRI. Standard MR imaging gives us exact location and characterization of the tumor by non invasive method. Characterization of spinal tumors will be more improved by development of newer MR imaging sequences in future. ${ }^{17}$

In our study, we have observed that there were 134 (74.4\%) cases positive for malignant spinal tumor on histopathology which showed that it's PPV as $74.4 \%$. Results of a study directed to see role of MRI in terms of diagnostic accuracy also matches with that of our study and reported the PPV of $87.1 \% .^{9}$

Buhmann with his colleagues reported that Sensitivity for MRI was $98.5 \%$, Specificity was $98.9 \%$ and the diagnostic precision developed in $98.7 \%$ for MRI confirming it to be highly sensitive for detection of spinal lesions suggesting to replace histopathology. ${ }^{18}$ Zeiser et al., reported that MRI showed marked specificity $(92 \%)$ and sensitivity $(100 \%)$ in spinal tumors detection. ${ }^{19}$ Abdel-Wanis et al, reported that sensitivity, specificity and accuracy of MRI were $97 \%, 98 \%$ and $98 \%$, respectively. ${ }^{20}$

But the PPV of MRI was reported to be low in another study conducted by Fouladi et al., i.e. 52\% which showed that it is not reliable and almost $50 \%$ cases have found to be negative. ${ }^{21}$

\section{CONCLUSION}

MRI is useful imaging tool for early prediction of spinal tumors. Furthermore, appropriate histopathological diagnosis can be predicted on basis of its imaging characteristics. Ultimately early diagnosis of spinal tumors will lead to early surgery and will prevent morbidity and mortality.

\section{REFERENCES}

1. Naganawa T, Miyamoto $K$, Hosoe H, Suzuki N, Shimizu K. Hemilaminectomy for removal of extramedullary or extradural spinal cord tumors: medium to long-term clinical outcomes. Yonsei Medical Journal, 2011; 52 (1): 121-9.

2. Izbudak I, Tekes A, Baez JC, Murphy K. Imaging of spinal tumors. Imaging in Oncology: Springer, 2008: p. 43-66.

3. Traul DE, Shaffrey ME, Schiff D. Part I: Spinal-cord neoplasms - intradural neoplasms. The Lancet Oncology, 2007; 8 (1): 35-45.

4. Abul-Kasim K, Thurnher MM, McKeever P, Sundgren PC. Intradural spinal tumors: current classification and MRI features. Neuroradiology, 2008; 50 (4): 301-14.

5. Rossi A, Gandolfo C, Morana G, Tortori-Donati P. Tumors of the spine in children. Neuroimaging Clinics of North America, 2007; 17 (1): 17-35.

6. Ali M, Khan Z, Sharafat S, Mehmood K, Khan P, Usman M. The spectrum of intradural spinal tumors. J Postgrad Med Inst. 2010; 24 (3).

7. Chung JY, Lee JJ, Kim HJ, Seo HY. Characterization of magnetic resonance images for spinal cord tumors. Asian Spine Journal, 2008; 2 (1): 15-21.

8. Beall DP, Googe DJ, Emery RL, Thompson DB, Campbell SE, Ly JQ, et al. Extramedullary intradural spinal tumors: a pictorial review. Current Problems in Diagnostic Radiology, 2007; 36 (5): 185-98.

9. De Verdelhan O, Haegelen C, Carsin-Nicol B, Riffaud L, Amlashi S, Brassier G, et al. MR imaging features of spinal schwannomas and meningiomas. Journal of Neuroradiology, 2005; 32 (1): 42-9.

10. Colli BO, Assirati Jr JA, Machado HR, Figueiredo JFdC, Chimelli L, Salvarani CP, et al. Intramedullary spinal cord paracoccidioidomycosis: report of two cases. Arquivos De Neuro-Psiquiatria. 1996; 54 (3): 466-73.

11. Tobias ME, McGirt MJ, Chaichana KL, Goldstein IM, Kothbauer KF, Epstein F, et al. Surgical management of long intramedullary spinal cord tumors. Child's Nervous System, 2008; 24 (2): 219-23.

12. Tihan T, Chi JH, McCormick PC, Ames CP, Parsa AT. Pathologic and epidemiologic findings of intramedullary spinal cord tumors. Neurosurgery clinics of North America, 2006; 17 (1): 7-11.

13. Senturk S, Guzel A, Guzel E, Bayrak AH, Sav A. Cervical spinal meningioma mimicking intramedullary spinal tumor. Spine, 2009; 34 (1): E45-E9. 
14. Lee M, Epstein FJ, Rezai AR, Zagzag D. Nonneoplastic intramedullary spinal cord lesions mimicking tumors. Neurosurgery, 1998; 43 (4): 788-94.

15. Pittella JEH. Nonneoplastic intramedullary spinal cord lesions mimicking tumors. Neurosurgery, 1999; 44 (6): 1365-6.

16. Brotchi J, Dewitte O, Balériaux D, Vandesteene A, Raftopoulos C, Flament-Durand J, et al. A Survey of 65 Tumors within the Spinal Cord: Surgical Results and the Importance of Preoperative Magnetic Resonance Imaging. Neurosurgery, 1991; 29 (5): 651-7.

17. Lowe GM. Magnetic resonance imaging of intramedullary spinal cord tumors. J Neurooncol. 2000 May; 47 (3): 195-210.

18. Buhmann S, Becker C, Duerr HR, Reiser M, BaurMelnyk A. Detection of osseous metastases of the spine: Comparison of high resolution multi-detector-CT with MRI. European Journal of Radiology, 2009; 69 (3): 567-73

\section{Additional Information}

Disclosures: Authors report no conflict of interest.

Ethical Review Board Approval: The study was conformed to the ethicalreview board requirements.

Human Subjects: Consent was obtained by all patients/participants in this study.

Conflicts of Interest: In compliance with the ICMJE uniform disclosure form, all authors declare the following.

Financial Relationships: All authors have declared that they have no financial relationships at present or within the previous three years with any organizations that might have an interest in the submitted work.

Other Relationships: All authors have declared that there are no other relationships or activities that could appear to have influenced the submitted work.

Address for Correspondence: Dr. Muhammad Usman Department of Neurosurgery, Lady Reading Hospital, MTI, Peshawar-Pakistan Email:drusman387@yahoo.com

\begin{tabular}{|c|c|c|c|}
\hline \multicolumn{4}{|c|}{ AUTHORSHIP AND CONTRIBUTION DECLARATION } \\
\hline Sr.\# & Author's Full Name & Intellectual/Contribution to Paper in Terms of: & Signature by the \\
\hline 1. & Hafeez-Ur-Rehman & 1. Proposed topics and methodology. & $\begin{array}{l}\text { author(s) } \\
\text { HAFEEZ-UR- }\end{array}$ \\
\hline 2. & Adnan Yousaf & 2. Data collection and calculations & REHMAN \\
\hline 3. & Muhammad Usman & 3. Analysis of data. & \\
\hline 4. & Muhammad Nouman Akram & 4. Literature review & \\
\hline 5. & Irum Habib & 5. Paper writing and Analysis of data & \\
\hline 6. & Sarfaraz Ahmad & 6. Study Design and surgeries & \\
\hline
\end{tabular}

Date of Submission: 02-02-2020

Date of Revision: 16-03-2020

Date of Online Publishing: 31-03-2020

Date of Print: 31-03-2020 